\title{
Predictors of maternal and neonatal complications in women with severe valvular heart disease during pregnancy in Tunisia: a retrospective cohort study
}

Rania Hammami ${ }^{1,2^{*}}$ (D) Mohamed Ali Ibn Hadj ${ }^{3}$, Yosra Mejdoub ${ }^{4}$, Amine Bahloul ${ }^{1,2}$, Selma Charfeddine ${ }^{1,2}$, Leila Abid $^{1,2}$, Samir Kammoun ${ }^{1,2}$, Abdallah Dammak ${ }^{3}$ and Kais Chaabene ${ }^{3}$

\begin{abstract}
Background: Severe valvular heart disease, especially stenosis, is a contraindication for conception according to the World Health Organization. This is still encountered in countries with a high rheumatic fever prevalence. The objective of this study was to determine predictors of maternal cardiac, obstetric and neonatal complications in pregnant women with severe valve disease.

Methods: This is an observational retrospective cohort study of all pregnant women with severe heart valvulopathy who gave birth between 2010 and 2017.

Results: We included 60 pregnancies in 54 women. Cardiac complications occurred during 37 pregnancies (61\%). In multivariate analysis, parity $(\mathrm{aOR}=2.41,95 \% \mathrm{CI}[1.12-5.16])$, revelation of valvulopathy during pregnancy $(\mathrm{aOR}=6.34$; $95 \% \mathrm{CI}[1.26-31.77])$, severe mitral stenosis $(\mathrm{aOR}=6.98,95 \% \mathrm{CI}[1.14-41.05]$,$) and systolic pulmonary arterial pressure$ $(\mathrm{aOR}=1.08,95 \% \mathrm{CI}[1.01-1.14])$ were associated with cardiac complications. Obstetrical complications were noted during 19 pregnancies (31.8\%). These complications were associated with nulliparity ( $\mathrm{OOR}=5.22 ; 95 \% \mathrm{Cl}[1.15-23.6]$ ), multiple valve disease $(a O R=5.26,95 \% \mathrm{CI}[1.19-23.2])$, systolic pulmonary arterial pressure $(a O R=1.04,95 \% \mathrm{CI}[1.002-$ 1.09]), and treatment with vitamin $\mathrm{K}$ antagonists $(\mathrm{aOR}=8.71,95 \% \mathrm{CI}[1.98-38.2])$. Neonatal complications were noted in $39.3 \%$ of newborns $(n=61)$ and these were associated with occurrence of obstetric complications $(\mathrm{aOR}=16.47$, 95\% CI[3.2-84.3]) and revelation of valvulopathy during pregnancy ( $\mathrm{aOR}=7.33,95 \% \mathrm{CI}[1.4-36.1])$.

Conclusions: Revelation of valvular heart disease during pregnancy is a predictor of not only cardiac but also neonatal complications. Valvular heart disease screening during pre-conceptional counseling is thus crucial.
\end{abstract}

Keywords: Pregnancy, Severe valvular heart disease, Neonatal complications, Prognosis

*Correspondence: raniahammami@yahoo.fr

${ }^{2}$ Research Unit UR 17ES37, Faculty of Medicine, University of SFAX, Sfax, Tunisia

Full list of author information is available at the end of the article

\section{Background}

Pregnancy is associated with several hemodynamic modifications which could disturb the function of the cardiac pump, especially in women with cardiac diseases. The prevalence of heart disease in pregnant women is estimated between 1 and 4\% [1,2]. According to the largest multicenter registry of heart diseases in pregnant women, "ROPAC", the most prevalent cardiac diseases 
are rheumatic valvular pathology in low- and middleincome, and congenital heart diseases in high-income countries [3, 4]. The World Health Organization (WHO) considers severe stenotic valvular heart diseases as a contraindication for conception (WHO IV category) [5]. Because rheumatic heart disease is still prevalent in Tunisia [6], managing pregnant women with such conditions is a daily challenge for obstetricians, cardiologists, and anesthesiologists. Clinicians thus have to deal with two main challenges: 1 . should they opt for termination of pregnancy due to the huge maternal and fetal risks? 2. what is the most appropriate mode of birth in case of continuation of pregnancy?

This study aimed at assessing both maternal and neonatal prognosis in pregnant women with at least one severe cardiac valve disease and identifying its risks.

\section{Methods}

This is an observational retrospective cohort study that includes a cohort of all consecutive pregnant women with at least one severe cardiac valve disease during the period between January 2010 and December 2017, managed in both cardiology and obstetric departments of Hedi Chaker Hospital in Sfax, Tunisia. Pregnancies in women with cardiac valve prosthesis, as well as pregnancies in women who had either spontaneous or voluntary abortions were excluded. Baseline clinical, electrocardiographic and echocardiographic variables were collected from the medical files and included: maternal age, educational level, parity, cardiac lesions, prior cardiac interventions, New York Heart Association (NYHA) functional class, cardiac rhythm, ventricular systolic function, valvular function, and pulmonary arterial systolic pressure. Severity of valve lesions was assessed according to the guidelines of the European Society of Cardiology [7].

Women were called to get information about both contraception use after birth and eventual new pregnancies before treating the cardiac valve disease.

Women who refused to give verbal consent were excluded.

Maternal cardiac complications were defined as maternal cardiac death, new episode of arrhythmia requiring treatment, heart failure, thromboembolic events, clinical overdose with anticoagulants, endocarditis and hospitalization for cardiac reasons during pregnancy and up to 1 week postpartum.

Obstetric complications were defined as maternal death for obstetric causes up to 1 week postpartum, gestational diabetes, preeclampsia, threatening preterm birth, premature rupture of membranes and postpartum hemorrhage.

Neonatal complications were defined as preterm birth $<37$ weeks, small-for-gestational-age $(<10$ th centile), hospitalization in the neonatology department, and early neonatal death.

Categorical variables are presented as frequencies and percentages while differences between groups are assessed using $\mathrm{X} 2$ tests. Continuous variables are presented as mean and standard deviation or as median and interquartile ranges as appropriate, and differences are assessed using Student's t-test or Mann-Whitney U tests depending on data distribution. Univariate analysis to identify predictors of adverse events was performed using chi-square, Fisher exact or Student's t-tests as appropriate. Univariate predictors of adverse events with $p$ values $<0.2$ were entered into a multivariate logistic regression model using backward elimination with a significant level of 0.05 and with adjusted odds ratios (aOR) with confidence intervals $95 \%$.

\section{Results}

Our cohort included 54 women with at least one severe valve disease and 60 pregnancies, leading to 59 spontaneous singleton births and one assisted twin birth (i.e. 61 newborns). During the study period, 80.624 births took place in our hospital. Six hundred thirty-nine cardiac ultrasound examinations were performed in pregnant women or during the first week after birth. The prevalence of valvular heart diseases was 6.7 per 10,000 births. Approximately 8.7 per 100.000 births had severe lesions.

Mean age of our cohort was $32.55 \pm 5.6$ years. More than half of the women were symptomatic of at least NYHA stage II dyspnea during the first trimester of pregnancy; however, $60 \%$ also showed anemia on their biological analysis. Baseline characteristics are shown in Table 1.

Pregnancy had revealed valvular disease in 31 women $(52 \%)$ and mean gestational age at diagnosis was $27 \pm 6.7$ weeks (range: $12-38$ weeks).

Median gestational age of birth was 38 weeks (range: $30-42)$; preterm birth occurred in 12 pregnancies (20\%) and there was only one case of $>42$ weeks. This woman was not aware of her valvulopathy which was discovered during labor following acute pulmonary edema.

Pulmonary edema disclosed valve disease in 21 women during pregnancy. In nearly half pregnancy was unplanned (31 women). In this group, only 13/31 women (41.9\%) used contraception at the time of conception (micro-progestatives in five women, intra-uterine device in one, and periodic abstinence in seven). The most prevalent valve disease was mitral stenosis (43/54, i.e. $79.6 \%$ ). Percutaneous mitral commissurotomy was indicated in 19 parturient women out of 43 . However, 11 of these women did not benefit from the procedure either because they refused it or because of a late, peripartum diagnosis of valvulopathy. Thus, this procedure was 
Table 1 Baseline characteristics of our population (54 women, 60 pregnancies, 61 Newborns)

\begin{tabular}{|c|c|c|}
\hline Age (years) & Total number & $32.55 \pm 5.6$ (range: $19-43)$ \\
\hline Rural origin & 54 women & 29 women $(53.7 \%)$ \\
\hline Educational level & 54 women & $\begin{array}{l}\text { Analphabetic (3.7\%), } \\
\text { primary }(59.2 \%), \\
\text { secondary }(42.5 \%), \\
\text { university }(5.5 \%)\end{array}$ \\
\hline Medical Antecedent & 60 pregnancies & \\
\hline Hypertension & & $5(8.3 \%)$ \\
\hline Diabetes & & $2(3.3 \%)$ \\
\hline Coronary diseases & & $1(1.6 \%)$ \\
\hline Idiopathic thrombocytopenia & & $1(1.6 \%)$ \\
\hline Parity & & $2.16 \pm 1.15$ (range $1-6)$ \\
\hline Gravidity & & $2.8 \pm 1.6$ (range $1-5)$ \\
\hline Obstetric Antecedent & 60 pregnancies & $43(71.6 \%)$ \\
\hline \multicolumn{3}{|l|}{ Previous CS } \\
\hline One previous CS & & $12(20 \%)$ \\
\hline Two previous CS & & $4(6.6 \%)$ \\
\hline \multicolumn{3}{|l|}{ Miscarriage } \\
\hline In Utero death & & $1(1.6 \%)$ \\
\hline Neonatal death & & $3(5 \%)$ \\
\hline Preeclampsia & & $4(6.6 \%)$ \\
\hline Gestational diabetes & & $2(3.3 \%)$ \\
\hline \multicolumn{3}{|l|}{ Dyspnea during the First Trimester } \\
\hline & 60 pregnancies & NYHA I: 30 (50\%) \\
\hline & & NYHA II: 25 (41.6\%) \\
\hline & & NYHA III: 5 (8.3\%) \\
\hline \multicolumn{3}{|l|}{ Diagnosis of valvular heart disease } \\
\hline Before pregnancy & 60 pregnancies & $29(48.3 \%)$ \\
\hline During Pregnancy & & $28(46.6 \%)$ \\
\hline During labor & & $2(3.3 \%)$ \\
\hline During the first week & & $1(1.6 \%)$ \\
\hline Anemia during pregnancy & 60 pregnancies & $40(66.6 \%)$ \\
\hline MS & 60 pregnancies & $43(71.6 \%)$ \\
\hline AS & & 7 women (11.6\%), \\
\hline MR & & 6 women (10\%), \\
\hline$M S+M R$ & & 1 patient (1.6\%), \\
\hline$M S+A R$ & & 1 patient (1.6\%), \\
\hline PS & & 1 patient (1.6\%) \\
\hline Mean PASP (mmHg) & 60 pregnancies & $50.8 \pm 16.03$ (range: $20-95)$ \\
\hline Anticoagulants in therapeutic dosage before or during pregnancy (\%) & 60 pregnancies & 19 women $(31.6 \%)$ \\
\hline \multicolumn{3}{|l|}{ Mode of birth } \\
\hline Cesarean & 60 pregnancies & $40(66.6 \%)$ \\
\hline Normal Vaginal birth & & $16(26.6 \%)$ \\
\hline Induced vaginal birth & & $3(5 \%)$ \\
\hline Gestational weeks at birth (median, min, max) & 60 pregnancies & 38 weeks (range:30-42) \\
\hline Maternal Cardiac complications & & $37(61.6 \%)$ \\
\hline Heart failure & 60 pregnancies & $30(50 \%)$ \\
\hline Arrhythmia & & $2(3.3 \%)$ \\
\hline Embolic events & & $2(3.3 \%)$ \\
\hline Anticoagulants overdose & & $3(5 \%)$ \\
\hline
\end{tabular}


Table 1 (continued)

\begin{tabular}{|c|c|c|}
\hline Age (years) & Total number & $32.55 \pm 5.6$ (range: $19-43$ ) \\
\hline Obstetrical complications & \multirow[t]{6}{*}{60 pregnancies } & $19(31.6 \%)$ \\
\hline Hemorrhage & & $3(5 \%)$ \\
\hline Preeclampsia & & $3(5 \%)$ \\
\hline Gestational diabetes & & $2(3.3 \%)$ \\
\hline Threatening preterm birth & & $12(20 \%)$ \\
\hline Premature rupture of membranes & & $1(1.6 \%)$ \\
\hline Neonatal complications & \multirow{4}{*}{$\begin{array}{l}61 \text { Newborns } \\
\text { (1 Twin) }\end{array}$} & $24(39.3 \%)$ \\
\hline Small-for-gestational-age & & $12(19.6 \%)$ \\
\hline Preterm birth & & $9(14.7 \%)$ \\
\hline Hospitalization & & $3(4.9 \%)$ \\
\hline
\end{tabular}

MS mitral stenosis, A S Aortic stenosis, MR mitral regurgitation, AR aortic regurgitation, $P S$ pulmonary stenosis, CS Cesarean Section, PASP mean pulmonary arterial systolic pressure

performed in only eight women with uncomplicated procedural courses. Among these women, there were seven vaginal births and one cesarean section following an obstetrical indication.

In 41 pregnancies (68\%), birth occurred by cesarean section. In three pregnancies, vaginal birth occurred assisted with oxytocin was performed as valvulopathy was discovered post-partum. Indication for cesarean section was cardiac in 30 pregnancies (73\%) and obstetrical in 11 pregnancies. Cesarean section was performed electively in most pregnancies $(n=36 ; 88 \%)$.

As far as newborns are concerned, median birth weight was $3000 \mathrm{~g}$ (range: $1500 \mathrm{~g}-3750 \mathrm{~g}$ ). Median Apgar score on the first minute was 9 (range: 3-9). Apgar score at 5 min was significantly lower in preterm than in full-term newborns: $7.16 \pm 1.61$ versus $8.66 \pm 0.73, p=0.01$.

All newborns had an Apgar score $\geq 7$ at $5 \mathrm{~min}$, except for one who was born from a first twin pregnancy, whose score was $=3$ at birth. He was hospitalized in neonatology for 17 days because of respiratory distress and the evolution was favorable.

In our population, 44 cardiac events occurred in 37 pregnancies (61.7\%). Most cardiac events $(n=35,79.5 \%)$ occurred antepartum, while the others occurred during labor or postpartum following discharge $(n=9,20.5 \%)$ (Tables 2 and 5). The most common cardiac complications were heart failure (in 36 pregnancies) and arrhythmias (23 pregnancies). Only one woman, with a twin pregnancy, had cardiac arrest because of ventricular arrhythmia $2 \mathrm{~h}$ after mitral commissurotomy. Severe hypokalemia was diagnosed and the woman was transferred to the intensive care unit with favorable recovery. At gestational age of 30 weeks, birth of the two babies took place by cesarean section.

Twenty-three obstetric events occurred in 19 pregnancies (31.8\%) (Tables 3 and 4). Concerning the 61 newborns, 27 fetal events occurred in 24 newborns (39.3\%) (Tables 5). On multivariate analysis predictors of neonatal complications were occurrence of obstetric events $(\mathrm{aOR}=16.47,95 \% \mathrm{CI}$ [3.2-84.3]) and the revelation of valve disease during pregnancy (aOR $=7.33,95 \%$ CI[1.4-36.1]) (Table 5). Overall, no maternal or neonatal death was observed. Three women showed preeclampsia and were treated with intravenous diuretics because of pulmonary edema.

Pregnancies with cardiac complications showed significantly more fetal events ( $51.4 \%$ versus $17.4 \%, p=0.009$ ) but no differences were observed in obstetric complications $(37.8 \%$ versus $21.7 \%, p=0.19)$.

The rate of preterm birth was $20 \%$ in our series (in 12 pregnancies). Two women had spontaneous preterm birth, while 10 had iatrogenic preterm births, nine of whom $(9 / 12=75 \%)$ had severe mitral stenosis. Pulmonary arterial pressure was significantly higher in those with preterm birth $(60.08 \pm 16.81$ versus $48.08 \pm 15.94 \mathrm{mmHg}, p=0.04)$. After 1 year, the index pregnancy, only 31 women used contraception (31/60 pregnancies $=51.7 \%)$. Among the other women, $6(10 \%)$ had a new pregnancy even before treating their severe valve heart disease.

\section{Discussion}

Our cohort analyzed the outcomes of pregnancies in women with severe heart valve disease, cardiac events occurred approximately in two women out of three, obstetric events occurred approximately in one women out three and neonatal events occurred in approximately 4 newborns out of 10 . The revelation of heart valve disease during pregnancy was a common predictor of both cardiac and obstetric eventsCardiovascular diseases are the most common causes of indirect maternal death during pregnancy and childbirth up to 6 weeks postpartum 
Table 2 Comparison of groups according to maternal cardiac complications

\begin{tabular}{llll}
\hline & MCC $+(\boldsymbol{n}=\mathbf{3 7})$ & MCC-( $=\mathbf{2 3})$ & $\boldsymbol{p}$ \\
\hline Mean Age (SD) & $33.4 \pm 5.5$ & $31.17 \pm 5.4$ & 0.13 \\
Rural origin (\%) & $22(59.5)$ & $23(30.4)$ & $\mathbf{0 . 0 2 9}$ \\
Low educational level (\%) & $26(70.3)$ & $8(34.8)$ & $\mathbf{0 . 0 0 7}$ \\
Parity & $2.45 \pm 1.21$ & $2.21 \pm 1.16$ & $\mathbf{0 . 0 3 8}$ \\
Gravidity & $3.16 \pm 1.81$ & $2.21 \pm 1.16$ & $\mathbf{0 . 0 1}$ \\
Nulliparity (\%) & $11(29.7)$ & $10(43.5)$ & 0.27 \\
Unwanted pregnancy (\%) & $21(56.7)$ & $9(39.1)$ & 0.184 \\
Unattended pregnancy (\%) & $29(79.3)$ & $20(87)$ & 0.31 \\
Hypertension before pregnancy (\%) & $3(8.1)$ & $2(8.6)$ & 0.64 \\
Valve disease revealed during pregnancy (\%) & $23(62.2)$ & $8(34.8)$ & $10(43.5)$ \\
NYHA 2 (\%) & $21(56.8)$ & $5(21.7)$ & 0.039 \\
Atrial fibrillation & $18(48.6)$ & $9(39.1)$ & 0.31 \\
Multiple valve disease (\%) & $19(51.4)$ & $11(47.8)$ & $\mathbf{0 . 0 3 7}$ \\
Severe MS (\%) & $32(86.5)$ & $5(21.7)$ & 0.35 \\
Severe AS (\%) & $5(13.5)$ & $6(26.1)$ & $\mathbf{0 . 0 0 1}$ \\
Severe MR (\%) & $4(10.8)$ & $1(4.3)$ & 0.31 \\
Severe AR (\%) & $1(2.7)$ & $61.13 \pm 2.2$ & 0.12 \\
LVEF (\%) & $57.4 \pm 7.2$ & $40.39 \pm 9.7$ \\
PASP (mmHg) & $57.29 \pm 15.8$ & $47.39 \pm 6.04$ \\
LA diameter (mm) & $52.72 \pm 7.35$ & $12(52.2)$ & \\
Anemia ((\%) & $24(64.9)$ & 0.62 \\
\hline ASAoric stos & 0.011 \\
\end{tabular}

AS Aortic stenosis, AR Aortic regurgitation, $L V E F$ Left ventricle ejection fraction, $L A$ Left atrium, MCC maternal cardiac complications, MS Mitral stenosis, MR Mitral regurgitation, NYHA New York Heart Association, PASP Mean pulmonary arterial systolic pressure

[2]. Knowledge of the risks associated with such conditions in pregnant women and their management is of pivotal importance. However, the number of published cases is limited and most recommendations are based on expert consensus with no strong level of evidence [8].

Tolerance of severe valvular heart diseases during pregnancy is little recognized since the prevalence of rheumatoid arthritis is decreasing. Nowadays, more and more women are getting pregnant at an older age, thus, the prevalence of pregnant women with severe cardiac valve disease remains high in low and middle income countries. The current study was carried out to evaluate the maternofetal outcomes in pregnant women with severe valve lesions. The recently published Global Rheumatic Heart Disease Registry (REMEDY) included 3.343 women with rheumatic heart disease in 12 African countries, India and Yemen; median age was 28 years [9]. The majority $(2137 ; 63.9 \%)$ had moderate to severe valvulopathy which was complicated by congestive heart failure in (705; $33.4 \%)$, pulmonary hypertension in $(599 ; 28.8 \%)$, atrial fibrillation in $(449 ; 21.8 \%)$, stroke in $(151 ; 7.1 \%)$, infectious endocarditis in $(86 ; 4 \%)$, and major bleeding in $(57 ; 2.7 \%)$. In 1.825 women of reproductive age (aged 12-51), only (65; $3.6 \%)$ used contraception. In a Tunisian study analyzing the epidemiological profile of cardiac women who gave birth in a Tunis maternity center between January 2010 and December 2012, out of 19.655 deliveries studied, the prevalence of heart disease was 1 in 351 deliveries ( $0.285 \%$; i.e., 56 women). Mean age was $30.89 \pm 5.3$ years (ranges between 21 and 42 years). Out of the 56 cases of cardiac women, 35 women (62.5\%) had valvulopathy, which translates into a prevalence of $0.17 \%$ [10]. In our cohort, the mean age was $32.5 \pm 5.6$ years and the prevalence of heart valve disease was about $0.49 \%$ while that of severe disease was estimated at $0.074 \%$.

Cardiac complications are frequent in pregnant women with cardiac valve diseases and vary between 13 and $35.6 \%$ according to previous studies [11-15] (Table 6). Certainly, the rate of complications should be higher in women with severe lesions, especially when the condition is discovered only during pregnancy. In the CAPREG II study, the overall maternal cardiac event rate during pregnancy for mWHO I (no increased risk), mWHO II (small increased risk), mWHO III (significantly increased risk), and mWHO IV (extremely high risk) was 3.1, 12.8, 21.1, and $35.6 \%$, respectively. In our cohort, two pregnancies out of three showed cardiac events. Pulmonary edema seems to be the most prevalent complication; nevertheless, the advancement of therapeutic strategies improved the prognosis. Maternal cardiac death became rare; in the 
Table 3 Comparison of groups according to obstetric complications

\begin{tabular}{|c|c|c|c|}
\hline & $\mathrm{OC}+(n=19)$ & OC- $(n=41)$ & $P$ value \\
\hline Mean Age (SD) & $34 \pm 4.61$ & $31 \pm 5.87$ & 0.15 \\
\hline Age $>35$ years (\%) & $9(47.4)$ & 14(34.1) & 0.32 \\
\hline Rural Origin (\%) & $8(42.1)$ & $21(51.2)$ & 0.51 \\
\hline Parity & $2.15 \pm 1.3$ & $2.17 \pm 1.09$ & 0.67 \\
\hline Nulliparity & $9(47.4)$ & $12(29.3)$ & 0.17 \\
\hline Gravidity & $2.84 \pm 1.67$ & $2.78 \pm 1.66$ & 0.88 \\
\hline Unwanted pregnancy (\%) & 10(52.6) & 20(48.8) & 0.78 \\
\hline Unattented pregnancy (\%) & $4(21.1)$ & $7(17.1)$ & 0.48 \\
\hline Hypertension (\%) & $2(10.5)$ & $3(7.3)$ & 0.51 \\
\hline Diabetes (\%) & $1(5.3)$ & $1(2.4)$ & 0.53 \\
\hline Pre-eclamptic Antecedent (\%) & $2(10.5)$ & $2(4.9)$ & 0.37 \\
\hline Previous Cesarean (\%) & $8(42.1)$ & $8(19.5)$ & 0.06 \\
\hline Previous Abortion (\%) & $5(26.3)$ & $8(19.5)$ & 0.39 \\
\hline Valve disease revealed during pregnancy (\%) & $7(36.8)$ & $24(58.5)$ & 0.11 \\
\hline NYHA $\geq 2(\%)$ & 10(52.6) & $2(51.2)$ & 0.91 \\
\hline Atrial fibrillation (\%) & 12(63.2) & $11(26.8)$ & 0.007 \\
\hline Maternal cardiac complications (\%) & 14(73.7) & 23(56.1) & 0.19 \\
\hline Multiple valve disease (\%) & 12(63.2) & 15(39) & 0.08 \\
\hline Severe MS (\%) & 15(78.9) & $28(68.3)$ & 0.39 \\
\hline Severe AS (\%) & $3(15.8)$ & $7(17.1)$ & 0.6 \\
\hline Severe MR (\%) & $3(15.8)$ & $7(17.1)$ & 0.609 \\
\hline Severe AR (\%) & $1(5.3)$ & $1(2.4)$ & 0.53 \\
\hline LVEF (\%) & $60.26 \pm 3.1$ & $58.19 \pm 6.98$ & 0.42 \\
\hline SAPS $(\mathrm{mmHg})$ & $57.1 \pm 16.9$ & $47.9 \pm 14.9$ & 0.03 \\
\hline LA diameter $(\mathrm{mm})$ & $53.5 \pm 8.02$ & $49.4 \pm 6.7$ & 0.05 \\
\hline Anemia (\%) & $11(57.9)$ & $25(61)$ & 0.82 \\
\hline Anticoagulant use (\%) & $11(57.9)$ & $8(19.5)$ & 0.003 \\
\hline Diuretic use (\%) & 12(53.6) & $15(80)$ & 0.08 \\
\hline Beta-blockers use (\%) & $6(40)$ & $4(14.3)$ & 0.057 \\
\hline Cardiac events (\%) & 14(73.7) & 23(56.1) & 0.19 \\
\hline
\end{tabular}

AS Aortic stenosis, AR Aortic regurgitation, LVEF Left ventricle ejection fraction, LA Left atrium, MS Mitral stenosis, MR Mitral regurgitation, NYHA New York Heart Association, PASP Mean pulmonary arterial systolic pressure, OC obstetric complications

recent CAPREG II study, it occurred in only 11 pregnancies $(0.6 \%)$ [12]. No cardiac death occurred during the practice of a tertiary care center including women with pulmonary hypertension, [16]. In our series, no maternal death was noted; only one case of cardiac arrest occurred because of hypokaliemia, and the recovery was obtained. However, cardiac mortality remains much higher than that in the obstetrical population [17-20].

Several studies tried not only to determine the predictors of cardiac events but also to analyze them in order to validate scores.

The multicentric CAPREG (Cardiac Disease in Pregnancy Study) including women both with congenital and acquired diseases, was the first to develop CAPREG Score. Predictors of cardiac events were: left heart obstruction, cyanosis or dyspnea before pregnancy, cardiac antecedents and systolic LV dysfunction [14, 21].
In the European Registry of Pregnancy and Heart Disease (ROPAC), including 2.966 women, valvular heart diseases account for $25 \%$ of pregnant women with cardiovascular disease. Mitral valve diseases - both stenosis and regurgitation - were the most common valvular lesions $(63 \%)$, followed by aortic valve disease $(23 \%)$ (Table 6). In this registry, signs of heart failure before pregnancy, atrial fibrillation and no previous cardiac intervention were strong predictors of cardiac events. In our cohort, cardiac complications occurred especially in stenotic lesions; regurgitant lesions were welltolerated and did not affect the possibility of carrying a pregnancy to full term. In stenotic lesions, increased cardiac output causes a significant rise in the transvalvular gradient of $50 \%$, mainly between the first and second trimesters [22]. That is why congestive heart failure occurs more commonly in the third trimester or early 
Table 4 Comparison of groups according to neonatal complications

\begin{tabular}{|c|c|c|c|}
\hline & $\mathrm{NC}+(n=24)$ & NC- $(n=37)$ & $P$ value \\
\hline Age (years) & $32.45 \pm 4.61$ & $32.54 \pm 6.09$ & 0.95 \\
\hline Rural origin (\%) & $12(50)$ & 17(45.9) & 0.75 \\
\hline Low educational level (\%) & 13(54.2) & $22(59.5)$ & 0.68 \\
\hline Parity & $2.29 \pm 1.04$ & $2.08 \pm 1.21$ & $0.3^{*}$ \\
\hline Gravidity & $3.04 \pm 1.65$ & $2.59 \pm 1.65$ & $0.24^{*}$ \\
\hline Unwanted pregnancy (\%) & 13(54.2) & 17(45.9) & 0.53 \\
\hline Unfollowed pregnancy (\%) & $4(16.7)$ & $7(18.9)$ & $1^{* *}$ \\
\hline Hypertension before pregnancy (\%) & $3(12.5)$ & $2(5.4)$ & $0.37^{* *}$ \\
\hline Valve disease revealed during pregnancy (\%) & 16(66.7) & $16(43.2)$ & 0.07 \\
\hline $\mathrm{NYHA} \geq 2(\%)$ & 14(58.3) & 17(45.9) & 0.34 \\
\hline Atrial fibrillation (\%) & $12(50)$ & $11(29.7)$ & 0.11 \\
\hline Maternal cardiac events (\%) & 20(83.3) & 18(48.61) & 0.006 \\
\hline Multiple valve disease (\%) & $11(45.8)$ & $17(45.9)$ & 0.99 \\
\hline Severe MS (\%) & 19(79.2) & $25(67.6)$ & 0.32 \\
\hline Severe AS (\%) & $3(12.5)$ & $7(18.9)$ & $0.7^{* *}$ \\
\hline Severe MR (\%) & $4(16.7)$ & $6(16.2)$ & $1^{* *}$ \\
\hline Severe AR (\%) & $1(4.1)$ & $1(2.7)$ & $1^{* *}$ \\
\hline LVEF (\%) & $57.95 \pm 8.49$ & $59.5 \pm 3.79$ & $0.7^{*}$ \\
\hline PASP $(\mathrm{mmHg})$ & $58.6 \pm 16.1$ & $45 \pm 13.8$ & $0.003^{*}$ \\
\hline LA diameter (mm) & $53.1 \pm 8.3$ & $49.29 \pm 6.2$ & 0.04 \\
\hline Anemia (\%) & $16(66.7)$ & $21(56.8)$ & 0.43 \\
\hline Hemoglobin (g/dl) & $10.15 \pm 1.22$ & $10.36 \pm 1.24$ & $0.37^{*}$ \\
\hline Anticoagulant use (\%) & $9(37.5)$ & $10(27)$ & 0.38 \\
\hline Cardiac events (\%) & $20(83.3)$ & 18(48.6) & 0.006 \\
\hline Obstetric events (\%) & $14(58.3)$ & $6(16.2)$ & 0.001 \\
\hline
\end{tabular}

AS Aortic stenosis, AR Aortic regurgitation, LVEF Left ventricle ejection fraction, LA Left atrium, MS Mitral stenosis, MR Mitral regurgitation, NC neonatal complications, NYHA New York Heart Association, PASP Mean pulmonary arterial systolic pressure

*test U-Mann Whitney

**Fisher test

Table 5 Predictors of maternal, obstetric and neonatal cardiac complications on univariate and multivariate regression

\begin{tabular}{|c|c|c|c|c|}
\hline \multirow{2}{*}{ Predictors of maternal complications } & \multicolumn{2}{|c|}{ Univariate regression } & \multicolumn{2}{|c|}{ Multivariate regression } \\
\hline & & & & \\
\hline & OR & Cl 95\% & $\mathrm{aOR}$ & Cl 95\% \\
\hline Parity & 2.09 & {$[1.14-3.82]$} & 2.41 & {$[1.12-5.16]$} \\
\hline Valve disease revealed during pregnancy & 3.08 & {$[1.04-9.11]$} & 6.34 & {$[1.26-31.77]$} \\
\hline Severe Mitral stenosis & 6.98 & {$[2-24.32]$} & 6.84 & [1.14-41.05] \\
\hline PASP (mmHg) & 1.1 & {$[1.04-1.16]$} & 1.08 & {$[1.01-1.14]$} \\
\hline \multicolumn{5}{|l|}{ Predictors of obstetric complications } \\
\hline Nulliparity & 2.17 & {$[0.7-6.69]$} & 5.22 & {$[1.15-23.6]$} \\
\hline Multiple valve disease & 2.67 & {$[0.87-8.24]$} & 5.26 & {$[1.19-23.2]$} \\
\hline PASP $(m m H g)$ & 1.03 & {$[1.001-1.076]$} & 1.04 & [1.002-1.09] \\
\hline Anticoagulant use & 5.67 & {$[1.71-18.7]$} & 8.71 & {$[1.98-38.2]$} \\
\hline \multicolumn{5}{|l|}{ Predictors of neonatal complications } \\
\hline Obstetric events & 7.2 & {$[2.1-23.8]$} & 16.47 & {$[3.2-84.3]$} \\
\hline Valve disease revealed during pregnancy & 2.6 & [0.9-7.6] & 7.33 & [1.4-36.1] \\
\hline
\end{tabular}

aOR adjusted Odds Ratio, $\mathrm{Cl}$ confidence Interval, OR Odds Ratio, PASP pulmonary arterial systolic pressure 
Table 6 Predictors of cardiac, obstetric, and fetal events in literature

\begin{tabular}{|c|c|c|c|c|}
\hline & CAPREG I (8) & ROPAC REGISTRY [3] & CAPREG II [12] & Our Study \\
\hline Study Period & 1994-1999 & 2008-2014 & $2001-2014$ & 2010-2017 \\
\hline Publication year & 2001 & 2016 & 2018 & - \\
\hline Methodology & $\begin{array}{l}\text { Prospective (Canadian } \\
\text { registry) }\end{array}$ & $\begin{array}{l}\text { Prospective (multicenter } \\
\text { European Registry) }\end{array}$ & $\begin{array}{l}\text { Prospective cohort } \\
\text { (Canadian registry) }\end{array}$ & Retrospective cohort \\
\hline Population & $\begin{array}{l}N=599 \text { (congenital and } \\
\text { acquired disease) }\end{array}$ & $N=2742, \mathrm{VHD}=865$ & $N=1938$ & $\begin{array}{l}N=60 \text { pregnancies in } 54 \\
\text { women with severe valve } \\
\text { disease, } 61 \text { newborns }\end{array}$ \\
\hline Age (years) & $28 \pm 6$ & $29.2 \pm 5.5$ & $30.6 \pm 5.6$ & $32.5 \pm 5.6$ \\
\hline MCC incidence & $13 \%$ & $20.6 \%$ & $16 \%$ & $61 \%$ \\
\hline $\begin{array}{l}\text { Independent Predictors of } \\
\text { MCC }\end{array}$ & $\begin{array}{l}{ }^{*} \text { Cardiac disease antecedent } \\
{ }^{*} \mathrm{NYHA} \geq 2 \text { /cyanosis } \\
{ }^{*} \text { Left heart obstruction } \\
{ }^{*} \text { LVEF } \leq 40 \%\end{array}$ & $\begin{array}{l}\text { *Pre-pregnancy signs of } \\
\text { heart failure } \\
\text { *in advanced countries. Atrial }_{\text {fibrillation and no previous }} \\
\text { cardiac intervention }\end{array}$ & $\begin{array}{l}\text { *Prior cardiac events or } \\
\text { arrhythmias. } \\
\text { *poor functional class or } \\
\text { cyanosis. } \\
\text { *high-risk valve disease/ } \\
\text { left ventricular outflow tract } \\
\text { obstruction. } \\
{ }^{*} \text { systemic ventricular dys- } \\
\text { function. } \\
\text { *no prior cardiac interven- } \\
\text { tions. *Mechanical valves. } \\
\text { *high-risk aortopathies. } \\
\text { *pulmonary hypertension. } \\
\text { *late pregnancy assesse- } \\
\text { ment }\end{array}$ & $\begin{array}{l}\text { *Parity } \\
\text { *Revelation of the valve } \\
\text { disease by pregnancy } \\
\text { *Mitral stenosis } \\
\text { *Systolic pulmonary } \\
\text { hypertension }\end{array}$ \\
\hline OC incidence & $7 \%$ & $8.4 \%$ & - & $31 \%$ \\
\hline $\begin{array}{l}\text { Independent Predictors of } \\
\text { OC }\end{array}$ & $\begin{array}{l}\text { *Primiparity } \\
\text { *Aortic coarctation. } \\
\text { *lupus } \\
\text { *Anticoagulant use. } \\
{ }^{*} \text { Cyanosis }\end{array}$ & $\begin{array}{l}\text { *Primiparity. } \\
\text { *hypertension before } \\
\text { pregnancy }\end{array}$ & - & $\begin{array}{l}\text { *Nulliparity } \\
\text { *PASP } \\
\text { *Anticoagulant use } \\
\text { *Multiple valve disease }\end{array}$ \\
\hline NC incidence & $20 \%$ & $23.7 \%$ & - & $39.3 \%$ \\
\hline $\begin{array}{l}\text { Independent predictors } \\
\text { of NC }\end{array}$ & $\begin{array}{l}\text { Multigestity } \\
\text { NYHA Il or cyanosis } \\
\text { Anticoagulant use } \\
\text { Tobacco use } \\
\text { Left heart obstruction }\end{array}$ & $\begin{array}{l}\text { Multigestity } \\
\text { Anticoagulant use } \\
\text { Pregnancy in underdevel- } \\
\text { oped countries }\end{array}$ & - & $\begin{array}{l}\text { Maternal cardiac compli- } \\
\text { cations } \\
\text { Valve disease revealed by } \\
\text { pregnancy }\end{array}$ \\
\hline
\end{tabular}

LVEF Left Ventricle Ejection Fraction, MCC maternal cardiac complications, NC Neonatal complications, NYHA New York Heart Association, OC obstetrical Complications, $V H D$ valve heart disease

postpartum period, whereas most arrhythmias occur in the antenatal period.

Mitral valve stenosis was usually not tolerated and was found to be an independent predictor of cardiac complications. In fact, the pregnancy period is characterized by an increase of cardiac output brought by increased heart rate and stroke volume, and oppositely, a decrease of peripheral resistance by peripheral vasodilatation. The drop of vascular resistance explains the tolerance of regurgitant lesions [6, 23-25].

Pregnancy outcomes in two large centers in the United States reported a risk of pulmonary edema occurrence in pregnant women with mild, moderate and severe mitral stenosis, between 11 and 24\%, 34 and $61 \%$, and 56 and $78 \%$. The rate of occurrence of atrial fibrillation varied between 0 and $7 \%$ in the case of mild stenosis, 10 and $22 \%$ in the case of moderate stenosis, and between 22 and 33\% in the case of severe lesions $[15,26]$.

Percutaneous mitral dilation seems to remarkably improve the hemodynamic condition of these women to an extent where even a vaginal delivery is made possible in most cases. According to the recent ESC guidelines, intervention should be considered before pregnancy in women with MS and valve area $<1.5 \mathrm{~cm}^{2}$ and should be considered in pregnant women with severe symptoms or systolic pulmonary artery pressure $>50 \mathrm{mmHg}$ despite medical therapy [8].

In our study, the revelation of cardiac valve disease during pregnancy was also found to be a strong predictor not only of cardiac complications but also of neonatal complications. This result accords with other predictors found in the ROPAC registry and the CAPREG II study which are lack of intervention before pregnancy as well 
as delayed pregnancy assessment. Therefore, it is strongly recommended to assess pre-pregnancy risk and to counsel all women with known or suspected congenital or acquired heart valve diseases and aortic disease [27]. It is also recommended to perform risk assessment in all women of childbearing age with cardiac diseases before, as well as after conception, using the mWHO classification of maternal risk [27]. Generally, women who receive late pregnancy assessment have more frequent adverse cardiac outcomes during pregnancy, which may be attributed to delayed access to appropriate risk stratification, follow-up, and management plan.

However, we noted that in our practice, even though the rate of illiteracy among women was low (3\%), use of contraception is infrequent. In our cohort, six women showed cardiac complications and became pregnant again before treating the heart valve diseases. The cardiologist plays a pivotal role in the therapeutic education of these women and the prescription of adequate contraception while discussing with the gynecologist.

The obstetrical risks remain poorly described in the literature. The main parameter to be evaluated is the mode of birth, which depends, in this context, on the maternal tolerance of pushing efforts and the possibility of epidural analgesia. According to the recent guidelines, a birth plan should be made between gestational age of 20-30 weeks, detailing of pregnancy detailing induction, management of labor, birth, and post-partum follow-up; Moreover, the induction of labor should be considered at 40 weeks of gestation in all women with cardiac disease [8].

Obstetric complications were 3 to 4 times more common in our population compared to the ROPAC and CAPREG studies (Table 6). Low parity (nulliparous or primiparous) is a predictor of obstetrical events in many studies, especially that it increases the risk of preeclampsia [28] (Table 6).

In our cohort, preterm labor threat was the most common complication. This was mainly due both to uterine muscle hypoxia and to acute heart failure, which were common occurrences in our women.

Pre-eclampsia was more common in women with aortic valve disease and left ventricle dysfunction because of low cardiac output and, as expected, in nulliparous women and those with pre-existing hypertension. In our series, all the cases of preeclampsia occurred in women treated with intravenous diuretics because of acute heart failure. This is a frequently faced challenge. The use of diuretics results in placenta hypoperfusion which is the main mechanism of preeclampsia; therefore, diuretics should be avoided in such women. The use of anticoagulants is also a predictor of obstetrical complications, mainly hemorrhage. In our cohort, this factor increased the risk of obstetrical events by 8 times. Indeed, the association between hemorrhage and anemia, frequently diagnosed in our women, worsens the prognosis and results in heart decompensation. It is therefore recommended to anticipate the timing of birth to ensure a safe and effective peripartum anticoagulation.

Neonatal prognosis is closely correlated with maternal prognosis. Anyway, in our series, we found the occurrence of obstetric complications $(\mathrm{aOR}=16.47,95 \%$ $\mathrm{CI}[3.2-84.3])$ and the revelation of valvulopathy during pregnancy $(\mathrm{aOR}=7.33,95 \% \mathrm{CI}[1.4-36.1])$ to be strong predictors of neonatal complications. In fact, the delayed discovery of valvulopathy may expose the fetus to a longer duration of hemodynamic stress, especially with a risk of placental hypoperfusion, hypotrophy, and prematurity. The immunological status of these newborns will also be precarious with a higher risk of hospitalization in the neonatal care unit. In the ROPAC registry, the rate of fetal complications among women with WHO IV heart disease was $31 \%$, which is comparable to the $40 \%$ rate in our series. Predictors of these complications in ROPAC were multigravidity, treatment with anticoagulants, diabetes and life in low income countries (Table 6).

Symptomatic women (NYHA class III-IV), and oral anticoagulants, were the main reasons for induced preterm birth. In the case of spontaneous prematurity, both inflammatory processes and utero-placental ischemia can initiate preterm labor [29]. Certainly, maternal hypoxia increases cytokines and oxygen free radicals, which may cause abnormal placentation; these conditions occurred mostly in women with congenital heart disease [30]. In our cohort, most cases of preterm birth were induced, which is why pulmonary systolic pressure was significantly higher in mothers of preterm babies. In a Japanese cohort including 857 women with cardiac disease, ischemic cardiac disease (48.3\%), and valvular heart disease (44.3\%) were related to the highest risk of induced prematurity. The rate of cesarean section was 81.7 and $68.8 \%$. In our series, we noted only $20 \%$ of preterm birth while previous studies (3-6) showed that both induced and spontaneous preterm births were less common in low income than in high income countries. This was explained by the advanced age with uterine dysfunction for spontaneous preterm birth and quicker access to obstetric care facilities in high income countries.

\section{Study limitations}

The main limitations of our study involved the retrospective design, on the one hand, and the small sample size on the other hand. These two limitations could be explained by the low prevalence of severe valve diseases among pregnant women as they contra-indicate conception. Moreover, we included only term-pregnancies since abortions and non-viable pregnancies are multifactorial 
which made us unable to conclude that there is a relationship between these obstetric events and the severity of valvulopathies.

\section{Conclusions}

To conclude, our cohort demonstrated that women with severe heart valve diseases should be counseled about pregnancy risks and fetal problems. It is crucial to early detect such cardiac lesions during premarital consultation through a meticulous interrogation and cardiac auscultation.

Since mitral stenosis is the most commonly encountered lesion, percutaneous treatment should be attempted whenever possible and performed by an experimented operator. This improves hemodynamic conditions and offers more chances of vaginal birth.

Moreover, obstetricians should give priority to vaginal delivery - with triggering if necessary, use epidural analgesia, if not contraindicated, and shorten birthing time, especially in women treated with anticoagulants.

Finally, in low and middle income countries, much more effort should be given to the organization of contraception campaigns in cardiac women, which necessitates close collaboration between both cardiologist and obstetrician.

\section{Abbreviations}

AR: Aortic regurgitation; AS: Aortic Stenosis; CS: Cesarean; Cl: Confidence Interval; LA: Left Atrium; LVEF: Left ventricle ejection fraction; MCC: Maternal cardiac complications; MR: Mitral regurgitation; MS: Mitral stenosis; NYHA: New York Heart Association; NC: Neonatal complications; aOR: Adjusted Odds ratio; OC: Obstetric complications; PS: Pulmonary stenosis; PASP: Mean pulmonary arterial systolic pressure; WHO: World Health Organization.

\section{Supplementary Information}

The online version contains supplementary material available at https://doi. org/10.1186/s12884-021-04259-6.

Additional file 1.

\section{Acknowledgments}

Not Applicable.

\section{Authors' contributions}

All authors assert having read and approved the manuscript. $\mathrm{RH}$ participated in the conception of the design of the study and wrote the paper. M A B: participated in the conception of the design of the study and collected the data and contacted the women by phone. Y M: participated in the conception of the design of the study and achieved the statistical analyses of the paper. $A B, S C, L A, S K, A D$, and KC: participated in the conception of the design of the study, reviewed and corrected the paper.

\section{Funding}

No funding was obtained for this study.

\section{Availability of data and materials}

All data generated or analyzed during this study are included in this published article and its supplementary information files.

\section{Declarations}

Ethics approval and consent to participate

This study was approved by the ethics committee of the Hedi Chaker Hospital in Sfax (Committee of Person Protection SUD, CPP Sud. The reference code of this study is $0245 / 2020$ ).

The ethics committee ruled that no formal consent was necessary as it is a retrospective study.

The head of cardiology department and gynecology department in the Hedi Chaker Hospital granted the administrative permissions to access to the medical records before starting the study.

\section{Consent for publication}

Not applicable (there are no images or other personal or clinical details of participants that compromise anonymity).

\section{Competing interests}

The authors declare having no competing interests.

\section{Author details}

${ }^{1}$ Department of Cardiology, Hedi Chaker Hospital, 3029 Sfax, Tunisia. ${ }^{2}$ Research Unit UR 17ES37, Faculty of Medicine, University of SFAX, Sfax, Tunisia. ${ }^{3}$ Department of Obstetrics \& Gynecology, Hedi Chaker Hospital, Sfax, Tunisia. ${ }^{4}$ Department of Epidemiology, Hedi Chaker Hospital, Sfax, Tunisia.

Received: 3 October 2020 Accepted: 9 November 2021

Published online: 08 December 2021

\section{References}

1. Elkayam U, Goland S, Pieper PG, Silverside CK. High-risk cardiac disease in pregnancy: part I. J Am Coll Cardiol. 2016;68(4):396-410.

2. Creanga AA, Berg CJ, Syverson C, Seed K, Bruce FC, Callaghan WM. Pregnancy-related mortality in the United States, 2006-2010. Obstet Gynecol. 2015;125(1):5-12.

3. van Hagen IM, Boersma E, Johnson MR, Thorne SA, Parsonage WA, Escribano Subías $P$, et al. Global cardiac risk assessment in the registry of pregnancy and cardiac disease: results of a registry from the European Society of Cardiology. Eur J Heart Fail. 2016;18(5):523-33.

4. van Hagen IM, Baart S, Fong Soe Khioe R, Sliwa-Hahnle K, Taha N, Lelonek M, et al. Influence of socioeconomic factors on pregnancy outcome in women with structural heart disease. Heart Br Card Soc. 2018;104(9):745-52.

5. Pijuan-Domènech A, Galian L, Goya M, Casellas M, Merced C, FerreiraGonzalez I, et al. Cardiac complications during pregnancy are better predicted with the modified WHO risk score. Int J Cardiol. 2015;195:149-54.

6. Triki F, Jdidi J, Abid D, Tabbabi N, Charfeddine S, Ben Kahla S, et al. Characteristics, aetiological spectrum and management of valvular heart disease in a Tunisian cardiovascular centre. Arch Cardiovasc Dis. 2017;110(8-9):439-46.

7. Baumgartner H, Falk V, Bax JJ, De Bonis M, Hamm C, Holm PJ, et al. 2017 ESC/EACTS guidelines for the management of valvular heart disease. Eur Heart J. 2017;38(36):2739-91.

8. Regitz-Zagrosek V, Roos-Hesselink JW, Bauersachs J, BlomströmLundqvist C, Cífková R, De Bonis M, et al. 2018 ESC guidelines for the management of cardiovascular diseases during pregnancy. Eur Heart J. 2018;39(34):3165-241.

9. Zühlke L, Engel ME, Karthikeyan G, Rangarajan S, Mackie P, Cupido B, et al. Characteristics, complications, and gaps in evidence-based interventions in rheumatic heart disease: the global rheumatic heart disease registry (the REMEDY study). Eur Heart J. 2015;36(18):1115-1122a.

10. Khemiri K, Jenayah AA, Boudaya F, Hamdi A, Meskhi S, Sfar E, et al. Profil épidémiologique des femmes enceintes cardiaques dans le centre de maternité de Tunis: expérience du service A. Pan Afr Med J. 2015;21(140):1-4

11. Aydin E, Ozyuncu O, Kasapoglu D, Orgul G, Ozer N, Yurdakok M, et al. Clinical analyses of 383 cases with maternal cardiac diseases. J Perinat Med. 2018;46(3):293-8. 
12. Silversides CK, Grewal J, Mason J, Sermer M, Kiess M, Rychel V, et al. Pregnancy outcomes in women with heart disease: the CARPREG II study. J Am Coll Cardiol. 2018;71(21):2419-30.

13. Wald RM, Silversides CK, Kingdom J, Toi A, Lau CS, Mason J, et al. Maternal cardiac output and fetal doppler predict adverse neonatal outcomes in pregnant women with heart disease. J Am Heart Assoc Cardiovasc Cerebrovasc Dis. 2015:4(11):1-11.

14. Siu SC, Sermer M, Colman JM, Alvarez AN, Mercier LA, Morton BC, et al. Prospective multicenter study of pregnancy outcomes in women with heart disease. Circulation. 2001;104(5):515-21.

15. Silversides CK, Colman JM, Sermer M, Siu SC. Cardiac risk in pregnant women with rheumatic mitral stenosis. Am J Cardiol. 2003;91(11):1382-5.

16. Dolgun ZN, Inan C, Sayin NC. Maternal and fetal outcomes in pregnancies with pulmonary hypertension: experience of a tertiary center. Taiwan J Obstet Gynecol. 2018;57(1):13-7.

17. Opotowsky AR, Siddiqi OK, D'Souza B, Webb GD, Fernandes SM, Landzberg MJ. Maternal cardiovascular events during childbirth among women with congenital heart disease. Heart Br Card Soc. 2012;98(2):145-51.

18. Lima FV, Yang J, Xu J, Stergiopoulos K. National trends and in-hospital outcomes in pregnant women with heart disease in the United States. Am J Cardiol. 2017;119(10):1694-700.

19. Briller J, Koch AR, Geller SE. Maternal cardiovascular mortality in Illinois, 2002-2011. Obstet Gynecol. 2017;129(5):819-26.

20. Hameed AB, Lawton ES, McCain CL, Morton CH, Mitchell C, Main EK, et al. Pregnancy-related cardiovascular deaths in California: beyond peripartum cardiomyopathy. Am J Obstet Gynecol. 2015;213(3):379.e1-10.

21. Martins LC, Freire CMV, Capuruçu CAB, Nunes M d CP, Rezende CA d L. Risk prediction of cardiovascular complications in pregnant women with heart disease. Arq Bras Cardiol. 2016;106(4):289-96.

22. Samiei N, Amirsardari M, Rezaei Y, Parsaee M, Kashfi F, Hantoosh Zadeh $\mathrm{S}$, et al. Echocardiographic evaluation of hemodynamic changes in leftsided heart valves in pregnant women with valvular heart disease. Am J Cardiol. 2016;118(7):1046-52.
23. Anthony J, Osman A, Sani MU. Valvular heart disease in pregnancy. Cardiovasc J Afr. 2016;27(2):111-8.

24. Garcia M, Mulvagh SL, Merz CNB, Buring JE, Manson JE. Cardiovascular disease in women: clinical perspectives. Circ Res. 2016;118(8):1273-93.

25. van Hagen IM, Thorne SA, Taha N, Youssef G, Elnagar A, Gabriel H, et al. Pregnancy outcomes in women with rheumatic mitral valve disease: results from the registry of pregnancy and cardiac disease. Circulation. 2018;137(8):806-16

26. Bhatla N, Lal S, Behera G, Kriplani A, Mittal S, Agarwal N, et al. Cardiac disease in pregnancy. Int J Gynaecol Obstet Off Organ Int Fed Gynaecol Obstet. 2003;82(2):153-9.

27. Roos-Hesselink JW, Budts W, Walker F, De Backer JFA, Swan L, Stones W, et al. Organisation of care for pregnancy in women with congenital heart disease. Heart Br Card Soc. 2017;103(23):1854-9.

28. van Hagen IM, Roos-Hesselink JW, Donvito V, Liptai C, Morissens M, Murphy DJ, et al. Incidence and predictors of obstetric and fetal complications in women with structural heart disease. Heart Br Card Soc. 2017:103(20):1610-8.

29. Adams Waldorf KM, Singh N, Mohan AR, Young RC, Ngo L, Das A, et al. Uterine overdistention induces preterm labor mediated by inflammation: observations in pregnant women and nonhuman primates. Am J Obstet Gynecol. 2015;213(6):830.e1-830.e19.

30. Pieper PG, Balci A, Aarnoudse JG, Kampman MAM, Sollie KM, Groen $\mathrm{H}$, et al. Uteroplacental blood flow, cardiac function, and pregnancy outcome in women with congenital heart disease. Circulation. 2013;128(23):2478-87.

\section{Publisher's Note}

Springer Nature remains neutral with regard to jurisdictional claims in published maps and institutional affiliations.
Ready to submit your research? Choose BMC and benefit from:

- fast, convenient online submission

- thorough peer review by experienced researchers in your field

- rapid publication on acceptance

- support for research data, including large and complex data types

- gold Open Access which fosters wider collaboration and increased citations

- maximum visibility for your research: over $100 \mathrm{M}$ website views per year

At BMC, research is always in progress.

Learn more biomedcentral.com/submissions 